\title{
Amino acid identification of Bombyx mori fibroin cocoon as biomaterial using liquid chromatography/mass spectrometry
}

\author{
Sartika Puspita ${ }^{1 *}$, Siti Sunarintyas ${ }^{2}$, Chairil Anwar ${ }^{3},{\text { Ema } \text { Mulyawati }^{4} \text {, and Marsetyawan HNE Soesatyo }}^{5}$ \\ ${ }^{1}$ Department of Oral Biology, School of Dentistry, Universitas Muhammadiyah Yogyakarta, Yogyakarta, Indonesia \\ ${ }^{2}$ Department of Dental Biomaterial, Faculty of Dentistry, Universitas Gadjah Mada, Yogyakarta, Indonesia \\ 3 Department of Chemistry, Faculty of Mathematics and Natural Science Universitas Gadjah Mada, Yogyakarta, Indonesia \\ 4 Department of Conservative Dentistry and Endodontic, Faculty of Dentistry Universitas Gadjah Mada, Yogyakarta, Indonesia \\ 5 Department of Histology and Cells Biology, Faculty of Medicine, Public Health, and Nursing, Universitas Gadjah Mada, \\ Yogyakarta, Indonesia
}

\begin{abstract}
A fibroin is a natural polymer that serves as a biomaterial because of the mechanical properties, biocompatible, biodegradable and amino acid composition. The mechanical properties of fibroin are influenced by crystalline structures of amino acid and are related to the amino acid composition. it can accelerate the wound healing because it promotes the proliferation of exposure tissue and inhibits inflammation. The study aimed to identify amino acid of Bombyx mori (B. mori) fibroin cocoon as biomaterial that was cultivated in Central Java Indonesia. Liquid Chromatography/Mass Spectrometry (LC/MS-Water, USA) was employed. This study found that fibroin of B. mori contains seventeen amino acids and the most abundant amino acid is L-Valin $4.81 \%\left(\mathrm{mg} \mathrm{kg}^{-1}\right)$.
\end{abstract}

Keyword: amino acid, Bombyx mori, dental material, fibroin, LCMS

\section{Introduction}

Recently, B.mori cocoon silk worm serves as a biomaterial because of its desirable nature and ingredients. A silk fiber is a natural polymer of protein produced by B.mori. It is composed of $65 \%$ to $75 \%$ coated fibroin protein with $20 \%$ to $30 \%$ sericin, an adhesive protein which reinforces the cocoon structure, and $5 \%$ wax, pigments, sugars and other impurities by the weight of silk worm cocoon [1]. The production of silk biomaterials involves removal of the sericin that surrounds the natural fibroin fibers [2]. A previous study reported that the biocompatibility of sericin was not highly excellent, thus the cytoviability of sericin towards human fibroblast cells was lower $(64.486 \%)$ [3] than cytoviability of fibroin towards human dental fibroblast pulp cells (104\% in $100 \%$ consentration) [4].

Fibroin has a good biocompatibility for human dental pulp cells and its ease of chemical modification $[1,4]$ and ability to be processed into several material formats either from aqueous solutions or organic solvents [1]. Fibroin was extracted from B.mori cocoon, sericin was degummed by dissolving it in hot alkaline water using $\mathrm{Na}_{2} \mathrm{CO}_{3}$ [2], then washed three times with Milli-Q water in a room temperature to remove the glueshaped protein sericin then make a silk fibroin solution by dissolving degummed silk into lithium bromide ( $\mathrm{LiBr})$ after that the fibroin solution was dialysis in Milli-Q water for $48 \mathrm{~h}$. To extend shelf life up to more than a year, the fibroin solution is stored in the freezer at $-80{ }^{\circ} \mathrm{C}$ for $1 \mathrm{~h}$ then placed in the lyophilizer for $24 \mathrm{~h}$ $[1,5]$.

Fibroin has high proportions of glycine, serine, and alanine. Fibroin contains a small amount of acid side chains of amino acids. The isoelectric point of silk fiber is around $\mathrm{pH}$ 5. There is a low proportion of amino acid residues with large chains in silk [6]. Silk fibroin is biocompatible, biodegradable, stable, and has mechanical properties as biomaterials [7]. A number of authors have reported analysis of trends in fibroin that demonstrated biomaterial application for tissue engineering such as suture materials, artificial vascular, artificial ligaments, cornea, wound healing dressing, and bone graft $[8,9]$. Fibroin contains 18 amino acids. Several studies reported that the adhesion functions are comparable to collagen substrates and can increase the growth of bone tissue in the bone graft and accelerate wound healing $[8,9]$. The authors become interested in the ability of fibroin as an organic material after reading the amino acid composition. Base on the previous research by robson (1985) in Mondal (2007) protein would be very important to adress or identified because of its contribution in the field of wound healing process. Thus, this study aimed to the identify amino acid of fibroin extracted from B.mori that was cultivated in Central Java Indonesia.

Liquid chromatography/mass spectrometry (LC/MS) has a powerful technology in drug discovery,

*Corresponding author: sartika.puspita@umy.ac.id 
including the characterization of target protein. This study will inform LCMS approaches in amino acid identification of B.mori fibroin [10].

\section{Materials and methods}

Figures and tables, B.mori cocoon raw material is obtained from Silkworm Cultivation Center, Central Java, Indonesia. The fibroin extraction employed a method based on Rockwood et al. (2011) [1]. An experimental study was conducted using Liquid Chromatography/Mass Spectrometry (LC/MS) in LPPT II UGM to identify the amino acid compositions of B.mori fibroin. Waters AcquityH UPLC ${ }^{\circledR}$ Class Quaternary Solvent Manager and Xevo TQD MS (Waters, USA) were employed for analysis.

A total sample of $2 \mathrm{~g}$ of fibroin was put into $50 \mathrm{~mL}$ screw tube and $10 \mathrm{~mL}$ of $\mathrm{HCl}$ was added to be then hydrolysed in an autoclave at $110^{\circ} \mathrm{C}$ for $12 \mathrm{~h}$, After that, the sample was neutralized with $50 \mathrm{~mL} 6 \mathrm{~N} \mathrm{NaOH}$, then filtered with $0.22 \mu \mathrm{M}$ and then LCMS is injected with $2 \mu \mathrm{L}$ of sample. The criterias or size of LCMS device are capillery $(3.5 \mathrm{kV})$, desolvation temperature $500{ }^{\circ} \mathrm{C}$, disolvation $1000 \mathrm{~L} \mathrm{~h}^{-1}$ and collision energy $15 \mathrm{~V}$. The mobile phase that used were $0.1 \%$ penta deca fluoro octanoic acid (PDFOA) $99.5 \%: 0.5 \%$ water $/ \mathrm{CH}_{3} \mathrm{CN}$ with $0.1 \%$ formic acid and $0.1 \%$ PDFOA, $10 \%: 90 \%$ water $/ \mathrm{CH}_{3} \mathrm{CN}$ with $0.1 \%$ formic acid by the flow $0.6 \mathrm{~mL} \mathrm{~min}^{-1}$.

\section{Results}

A Liquid Chromatography/Mass Spectrometry (LC/MS) was employed to identify the amino acids of B.mori fibroin. LC/MS is combination of Liquid Chromatography (LC) and Mass Spectrometry (MS) and it is a powerful analytical technique with very high sensitivity and specificity. The Liquid Chromatography (LC) is able to separate components of sample and then the sample eluents into Mass Spectrometry (MS) where the detection, identification and determination of components masses can be carried out in presence of other components.

LC/MS is used in determination of pharmaceutical drug substances, intermediates and its related compounds for quantitative and qualitative purpose. LC-MS is used most significantly in in-vitro dissolution, bioequivalence, bioavailability and metabolite studies [6]. Amino acid identification of B. mori fibroin is shown in Table 1. Table 1 shows that L-Valine is the most abundant amino acid while L-Methionine is the least amino acid because it was not detected in this sample.
Table 1. Amino acid identification of B. mori silk fibroins using Liquid Chromatography Mass Spectrometry (LCMS)

\begin{tabular}{l|l|l|l}
\hline No & Amino Acid & $\left(\mathbf{m g ~ k g}^{-\mathbf{1}}\right)$ & $\mathbf{\%}$ \\
\hline 1 & L-Arginine & 14795.92 & 1.48 \\
\hline 2 & L-Histidine & 4875.44 & 0.49 \\
\hline 3 & L-Lycine & 8836.56 & 0.88 \\
\hline 4 & L-Phenylalanine & 22710.97 & 2.27 \\
\hline 5 & L-Isoleucine & 18547.60 & 1.85 \\
\hline 6 & L-Leucine & 11839.60 & 1.18 \\
\hline 7 & L-Tyrosine & 11275.75 & 1.13 \\
\hline 8 & L-Methionine & ndd & ndd \\
\hline 9 & L-Valine & 48142.67 & 4.81 \\
\hline 10 & L-Proline & 329.15 & 0.03 \\
\hline 11 & L-Glutamic acid & 1184.01 & 0.12 \\
\hline 12 & L-Aspartic acid & 731.13 & 0.07 \\
\hline 13 & L-Cysteine & 39.64 & 0.00 \\
\hline 14 & L-Threonine & 701.27 & 0.07 \\
\hline 15 & L-Serine & 6573.55 & 0.66 \\
\hline 16 & L-Alanine & 27623.30 & 2.76 \\
\hline 17 & L-Glycine & 25720.17 & 2.57 \\
\hline
\end{tabular}

As shown in Table. 1, it is important to know that amino acids have functional groups, carboxylic acids and amino acids. In one $\alpha$-amino acid, both are attached to the same carbon $(\alpha-)$ atom. Proteins are made up of 20 amino acids. Complete hydrolysis of proteins produces twenty L- $\alpha$ - amino acids. Although some amino acids found in proteins are dextrorotatory and some are levorotatori at $\mathrm{pH}$ 7.0, they have absolute Lglyceraldehyde configurations so they become L- $\alpha$ amino acids [11]. The chromatogram of L-valine as follows:

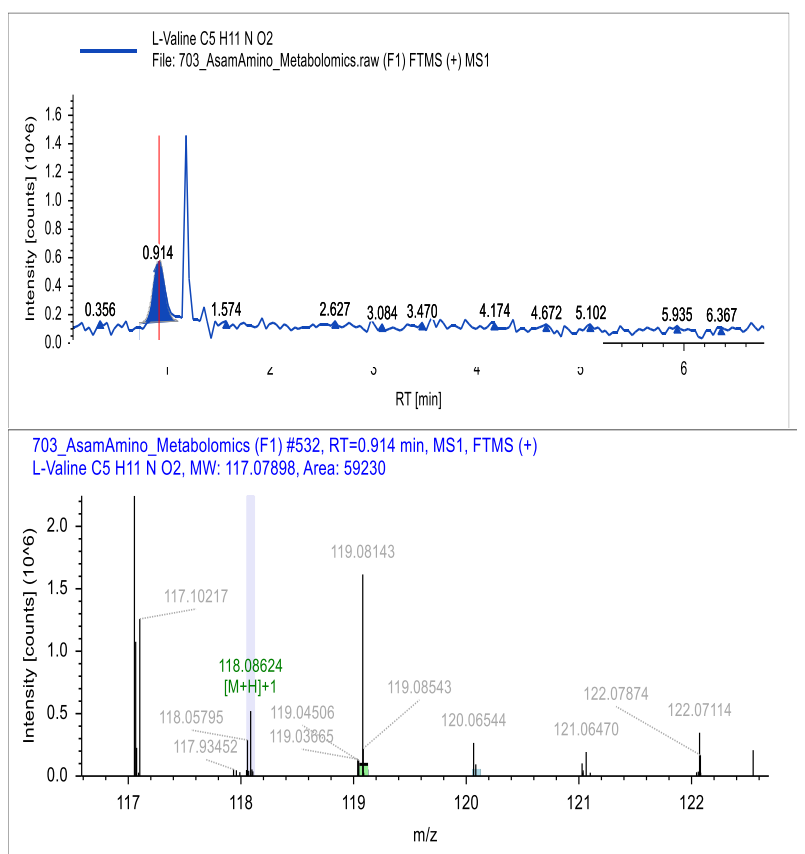

Fig. 1. Chromatogram of L-Valine that the most abundant amino acid composition in the fibroin B.mori 


\section{Discussion}

Fibroin is a natural fiber obtained from silkworms, one of two main kinds of silk protein have been investigated extensively for biomedical applications and tissue engineering. Notable features of fibroin include a high biocompatibility, biodegradability, a limited inflammatory response, and excellent mechanical properties [9]. It is interesting to note that amino acid can be identified using silk fibroin from various sources [12].

A silk fibroin is a crystalline protein fiber consisting of light chain and a heavy chain linked by dissulfide bond. The silk fibroin is a block copolymer rich in hydrophobic beta sheet-forming block linked by small hydrophilic linker segments or spacers. The crystalline regions are primarily composed of glycine- $X$ repeat where $X$ could be alanine, serine, threonin or valine. In the domains lie subdomains that are rich in glycine, alanine, serine and thyrosine. The result is that a hydrophobic protein can self-assemble to form strong and resilient materials. The dominance of the beta sheet forming regiment with in fibroin structure impact the protein based materials with high mechanical strength and toughness. The toughness of silk fiber is greater than the best synthetic material including kevlar [1].

The Silk fibroin has a thin, long, light and soft fiber. It is well known for its water absorbency, dyeing affinity, thermo tolerances, insulation properties and luster. In the field of biomaterial, it can be used as the raw material for artificial blood vessels, artificial ligament, bone graft, cornea, eye drop and surgical sutures $[6,8]$. Fibroin of B.mori is also able to accelerate wound healing and growth of tissue due to amino acid contents especially valine as a most abundant of amino acid composition of fibroin as Taya et al. research reported that valine are essential for the proliferation and maintenance of hematopoietic cells or mesenchimal cells so that it can enhance differentiate into cells that support the repair or the healing process $[8,9,11,13]$.

The most abundant amino acid in B.mori fibroin is L-Valine while the least amino acid is L-Methionine with a total of 17 amino acids as shown in Table 1. The finding of this study was similar with a previous study by Robson (1985) in Mondal (2007) except the composition of L-Tryptophan. In this study LTryptophan is very low concentration so that undetecable by LCMS.

The finding of current study revealed that the amino acid of B.mori fibroin from Silkworm Cultivation Center Central Java Indonesia (Figure 1) was different in number and composition with the previous study (Figure 2). A factor thought to be influencing the difference is geographical location that affects the silkworm food vegetation including mulberry leaves. The previous study was conducted in India while this study was in Indonesia.

A total of seventeen amino acids from B.mori (Table 1) consist of L-Alanine, L-Phenylalanine, LIsoleucine, L-Leucine, L-Methionine, L-Proline, LValin (non polar amino acid) and L-Arginine, LAspartic acid, L-Histidine, L-Lycine, L-Tyrosine, LGlutamic acid, L-Cysteine, L-Threonine, L-Serine, L-
Glycine (polar amino acid). The division of amino acids is based on an R chain attached to either a polar or nonpolar of $\alpha$-carbon atom. Based on amino acid solubility the polar group can be easily soluble in water and ethanol while non-polar groups are easily soluble in benzene, hexane and ether [11].

LC/MS/MS experiments can be performed on selected peptide ions. It is important to note that accurate mass determination coupled with LC/MS retention time can be very useful in identifying peptides in complex mixtures. In the case of complex protein mixtures, prefractionation techniques are often used before further protein characterization including ion-exchange, hydrophobic interaction chromatography and affinity chromatography. After the prefractionation of the samples in this study, collected fractions can be further separated and analyzed by LC/MS [12]. In this study it is important to know the amino acid content in fibroin of B.mori because these components will affect the healing process as a biomaterial.

L-Valin is an essential amino acid that has the most abundant in B.mori fibroin. L-Valin amino acid is very important substance for the wound healing process because it plays a role in the regeneration of cells. It is needed for repair process based on the previous research [13]. The result of this study is very interesting so that fibroin have prospect in future for using it as various biomaterials.

\section{Conclusion}

Fibroin of B.mori consist of seventeen amino acids there are L-Alanine, L-Phenylalanine, L-Isoleucine, LLeucine, L-Methionine, L-Proline, L-Valin, L-Arginine, L-Aspartic acid, L-Histidine, L-Lycine, L-Tyrosine, LGlutamic acid, L-Cysteine, L-Threonine, L-Serine, LGlycine (polar amino acid) and the most abundant amino acid is L-Valin $4.81 \%\left(\mathrm{mg} \mathrm{kg}^{-1}\right)$.

The authors acknowledge the financial support from Universitas Gadjah Mada Publishing Beureu, Yogyakarta, Indonesia with the grant number 2127/UNI/DITLIT/DITLIT/LT/2019.

\section{References}

1. D.N. Rockwood, R.C. Preda, T. Yücel, X. Wang, M.L. Lovett, D.L. Kaplan, Nat Protoc., 6, 10, 16121631 (2011).

2. T.-T. Cao, Y.-J. Wang, Y.-Q. Zhang, PLoS One, 8, 6 (2013).

3. S. Sunarintyas, W. Siswomihardjo, A.E. Tontowi, International Journal of Biomaterials, 2012, 1-5 (2012).

4. S. Puspita, M.H. Soesatyo, S. Sunarintyas, E. Mulyawati, The fibroin (Bombyx mori L.) is cytocompatible with human primary pulp cells, presented at the 1st International Conference On Bioinformatics, Biotechnology, and Biomedical Engineering (Biomic 2018), Yogyakarta, Indonesia, p. 020018 (2019). 
5. R.C. Preda, G. Leisk, F. Omenetto, D.L. Kaplan, Bioengineered silk proteins to control cell and tissue functions, In: Protein Nanotechnology, vol. 996, J.A. Gerrard, Ed. Totowa, NJ: Humana Press, (2013), p. 19-41.

6. M. Mondal, K. Trivedy, S.N. Kumar, The silk proteins, sericin and fibroin in silkworm, Bombyx mori Linn., - a review, p. 14 (2014).

7. M.K. Sah, K. Pramanik, IJESD, 404-408 (2010).

8. W. Abdel-Naby et al., PLoS ONE, 12, 11, e0188154, (2017).

9. H.W. Ju et al., International Journal of Biological Macromolecules, 85, 29-39, (2016).

10. V.W. Rodwell, D.A. Bender, K.M. Botham, P.J. Kennelly, P.A. Weil, Harper's illustrated biochemistry. USA: McGraw-Hill Education (2019).

11. D.B. Khadka, D.T. Haynie, Nanomedicine: Nanotechnology, Biology and Medicine, 8, 8, 1242-1262, (2012).

12. G. Chen, B.N. Pramanik, Drug Discovery Today, 14, 9-10, 465-471, (2009).

13. Y. Taya, Y. Ota, A.C. Wilkinson, A. Kanazawa, H. Watarai, M. Kasai, H. Nakauchi, S. Yamazaki, Science, 354, 6316, 1152-1155, (2016). 